\title{
The Problem of Sports Betting in Kenya: Striking a Balance between Private Profit and Public Good
}

\author{
Victoria Gitau*
}

\begin{abstract}
The inception of sports betting in Kenya has brought forth great excitement to prospective bettors and shrewd betting operators which has resulted in an equal amount of controversy and muddle. This note seeks to address the conflict between the private profit that investors and the economy reap, and the public good that the state owes its citizens by virtue of its fiduciary duty over its people. The author scrutinises the current law of sports betting in Kenya to demonstrate that it is not sufficient to speak to the two conflicting issues and that a concession is possible.
\end{abstract}

Keywords: Sports betting, Betting Gaming and Lotteries Act, private profit, public good

\section{Introduction}

Historically, gambling has been frowned upon as an activity that encourages vices rather than virtues; it has therefore been prohibited by law. ${ }^{1}$ During the Dark Ages, the church opposed secular engagements and hence attempted to place restrictions on games of chance. ${ }^{2}$ This was partially because at the time gaming was perceived to have been rooted in pagan religion, a sacrilege, as it bore an interconnection with the gods of old who were, by then, meant to be a long forgotten taboo. This spectacle did not go down well with the divines who wrote and preached against games of chance, but fate had it that such games

\footnotetext{
* The author is an LLB student at Strathmore Law School.

$1 \quad$ Hurt C, 'Regulating public morals and private markets: Online securities trading internet gambling and the speculation paradox' Brigham Young University Law Review, 2006, 374.

2 David F, Games, gods and gambling, Hafner Publishing Company, New York, 1962, 30.
} 
would thrive. ${ }^{3}$ Pre-classical theorist Khaldun also conveyed indifference if not utter disdain for people who put their fortunes in the whims of chance. ${ }^{4}$

This mentality has been carried forward to modern times, evident for instance in the United States where gambling was illegal by default and that it has only recently been allowed the 'privilege' of being restricted to select geographical locations and regulatory control for its operation. ${ }^{5}$ This has one difference with the Kenyan situation: sports betting in Kenya has not been regulated adequately. In fact, despite other available methods of regulation, taxation, with its attendant controversies as outlined in this note, has been utilised the most.

As of now, steps have been taken to legalise gambling in many parts of the world. ${ }^{6}$ Gambling has been legal in Kenya with the inception of the Betting Lotteries and Gaming Act (BLGA) ${ }^{7}$ aimed at controlling the upcoming industry with a view to protect society from the vice. ${ }^{8}$ Mutuku rightly reiterates pertinent parliamentary proceedings:

'The control of this human weakness is more desirable than turning a blind eye to it. At the moment, all that is required is a blackboard and a piece of chalk; and a bookmaker can operate. (He opens his books quite happily one morning with little or no capital at all, and waits until a punter, that is some member of the public, wins a large sum of money). He then closes down and disappears, leaving the disappointed and unpaid client. The aim of this Bill, Mr Speaker, is to eliminate these unscrupulous persons from the scene of gambling (including betting and lotteries) in order to enable the public to have a fair deal'?

The Betting Control and Licensing Board (BCLB) registers and licenses betting companies and provides for the cancellation or suspension of any such licence subject to conditions laid out. ${ }^{10}$ It is also tasked with the duty of inquiring into complaints against licensees and permit holders. ${ }^{11}$

David F, Games, gods and gambling, 30.

4 Khaldun I, Muqaddimah, 486, - <https://asadullahali.files.wordpress.com/2012/10/ibn_khaldunal_muqaddimah.pdf. Here Ibn Khaldun expresses that collecting hidden treasures is not a natural way of making a living. Those who take part in it are weak-minded people unable to make a living using natural means such as crafts or commerce. Devious means are employed as a way of maintaining a lifestyle of undeserved luxury at all costs.

5 Hurt C, 'Regulating public morals and private markets: Online securities trading internet gambling and the speculation paradox' 86(2)Boston University Law Review, 2006, 373-374.

6 Hurt C, 'Regulating public morals and private markets', 440.

7 Betting Lotteries and Gaming Act (Act No. 9 of 1966).

8 Mutuku M, 'The regulatory regime governing the casino industry in Kenya: A need for reforms' Unpublished LLM Thesis, University of Nairobi, Nairobi, 2013, 47.

9 House of Representatives Hansard Report, January 1966, column 27 as cited by: Mutuku M, 'The regulatory regime governing the casino industry in Kenya: A need for reforms', 47.

10 Section 3, Betting, Lotteries and Gaming Act (Act No.9 of 1966).

11 Section 4, Betting, Lotteries and Gaming Act (Act No.9 of 1966). 
The popularity of gambling in Kenya is at an all-time high, particularly online gambling and sports betting. ${ }^{12}$ As mentioned in brief by Anderson, Blackman, Siekmann and Soek, it is common to come across a popular football player on a billboard clad in his jersey endorsing a sports betting company. ${ }^{13}$ Sports betting has received overwhelming reception from Kenyans since 2013 when SportPesa pioneered the industry by acquiring a licence from BCLB. ${ }^{14}$ Needless to say, the sports betting industry has grown enormously with companies such as Betin, Betway, mCHEZA and more following suit. By 2014, PricewaterhouseCoopers (PwC) cited an expected growth of 6.8 percent to 25.6 million US dollars by 2018. Commendably, not only has the Gross Domestic Product (GDP) of the country been boosted by the economic activity through taxation as provided by law, but has also provided employment opportunities. ${ }^{15}$

Kenya has a rapidly growing industry in a fairly unfamiliar territory and the controls that should be put in place for its regulation are neither forthcoming nor commensurate to it. ${ }^{16}$ These are tell-tale signs of a 'social problem volcano' awaiting eruption. This is probable given the steady increase of actors in an unregulated industry and its many social evils; explaining why some youth have committed suicide as a result of regrettable financial overinvestment in sports betting and subsequent loss. ${ }^{17}$ The problem is whether recent attempted developments in law and policy-making are correct in doing what betting operators deem as effectively creating a hostile environment for their industry operations, with the aim of ridding the country of the vice of gambling at their expense.

This note analyses the pertinent issues in the following order. The first part critiques the clauses in the Budget $(2017)^{18}$ regarding betting tax, as well as the proposed Betting, Lotteries and Gaming (Amendment) Act. The second part examines the socio-economic effects of sports betting on the country while the third part analyses other important considerations in the gambling industry that affect the nation. Resolutions are put forward in the fourth part aimed at striking

12 Koross R, 'University students gambling: Examining the effects of betting on Kenyan university students' behaviour' 4(8) International Journal of Liberal Arts and Social Sciences, 2016, 57.

13 Anderson M, Blackshaw S, Siekmann C, Soek J, Sports betting: Law and policy, 1ed, ASSER International Sports Law Centre, The Hague, 2012, vii.

14 Koross R, 'University students gambling', 57.

15 Obiukwu O, 'Gambling in Africa: Is this prospering enterprise worth the addiction cost?' Ventures Africa, 9 December $2014-<$ http://venturesafrica.com/gambling-in-africa-is-this-prosperingenterprise-worth-the-addiction-cost/> on 12 June 2017.

16 Gemba A, 'Implications of sports betting in Kenya: Impact of robust growth of the betting industry' Unpublished MBA Thesis, United States International University Africa, Nairobi, 2017, 1.

17 Koross R, 'University students gambling', 59.

18 The National Treasury, Budget Statement for the Fiscal Year 2017/2018, 30 March 2017. 
a balance, if possible, between the economic flourishing of the sports betting industry and the social welfare of the Kenyan people for the overall good of the nation.

\section{Recent Regulatory Developments}

As will be validated in this note, the industry does not have sufficient checks in place to equal its growth or prevalence. A regulatory vacuum inspired the sponsorship of the Betting Lotteries and Gaming (Amendment) Bill ${ }^{19}$ by Member of Parliament Jakoyo Midiwo. ${ }^{20}$

The Bill proposed the incorporation of additional provisions to the Act that laid emphasis on proposing additional taxation measures rather than alternative regulatory measures. The first additional taxation provision was made as follows: contrary to the initial betting tax which was levied at a rate of 7.5 percent $^{21}$ of the gaming revenue $e^{22}$ a revised rate of 7.5 percent of the gross betting revenue was proposed. ${ }^{23}$ The proposed amendment introduced yet another tax: the prize competition tax which would be levied on the cost of entry to a competition at a premium rate of 15 percent of the total gross turnover. ${ }^{24}$

Midiwo stated that the industry was in dire need of regulation. ${ }^{25}$ Critics questioned whether the amendment would aid in the regulation of betting in Kenya if it was passed, as the major regulatory sections it included were the aforementioned provisions on taxes. ${ }^{26}$ Kenyans on social media questioned whether heavy taxation is the only way of controlling and regulating the industry, or whether it is valid while the motives of proposing the taxes have not been justified.

19 Betting, Lotteries and Gaming (Amendment) Bill (2016).

20 The Bill by Jakoyo Midiwo is tabulated as number 35 on the online repository of Kenya Law Reports. See $-<$ http://kenyalaw.org/kl/index.php?id=5991>.

21 Section 29A, Betting Lotteries and Gaming Act (Act No. 9 of 1966).

22 Gaming revenue is gross turnover minus the amount of money paid out to customers as winnings. Gross turnover is the amount of money made by a bookmaker due to betting transactions. Gross betting revenue is the total amount of money a betting firm makes during betting transactions. See Section 79, Finance Act (Act No. 38 of 2016). The following section also details on the calculation of gaming revenue and differentiates it from net profit.

23 Section 3, Betting, Lotteries and Gaming (Amendment) Bill, 2016.

24 Section 6, Betting, Lotteries and Gaming (Amendment) Bill, 2016.

25 Agutu N, 'KOT attack Midiwo over betting bill, say he wants money from companies' The Star Newspaper, 21 February 2017-<http://www.the-star.co.ke/news/2017/02/21/kot-attackmidiwo-over-betting-bill-say-he-wants-money-from-companies_c1510728> on 12 June 2017.

26 - <http://www.the-star.co.ke/news/2017/02/21/kot-attack-midiwo-over-betting-bill-say-hewants-money-from-companies_c1510728> on 12 June 2017. 
There was much hostility from the Association of Gaming OperatorsKenya (AGOK) who felt unfairly targeted by the Bill and claimed that it was 'fundamentally flawed'. ${ }^{27}$ The National Assembly Labour and Social Welfare Committee (NALSWC) asked for the Bill to be shelved for lack of stakeholder consultation. $^{28}$

Commissioner General of the Kenya Revenue Authority (KRA), John Njiraini tackled the issue at a press conference and addressed the NALSWC stating that there would be negative effects to tax collection in the country by driving investors away, a matter detrimental for revenue collection. The sector has contributed to a great amount of tax collection by the KRA. Between 2014 and 2017 KRA collected 4.7 billion Kenyan Shillings from gambling activities and it expressed its expectation of collecting 3.4 billion Kenyan Shillings in the Fiscal Year (FY) 20172018. In addition to that, revenue from this sector increased by 0.4 billion Kenyan Shillings (FY 2015-2016). Njiraini advised that the sector should be regarded as any other business by being allowed a good environment for operation. ${ }^{29}$

Some legislators such as the Kipipiri Member Of Parliament (MP) conveyed his suspicion about the 'undue pressure to pass the law for the sake of unclear motives'. He further attributed his dismay to the fact that stakeholder engagement ${ }^{30}$ was contrary to the procedures laid out in the law. ${ }^{31}$ One might wonder: was the Bill simply a politicised one only considering party interests? For instance, Midiwo, the then deputy leader of the minority, made a disclaimer that he would not support a similar government-sponsored Bill as such a step would be carried out in order for the government of the day to steal the shine of the opposition. ${ }^{32}$

27 Mbaka J, 'Betting firms oppose Midiwo Bill, claim it's fundamentally flawed' The Star Newspaper, 17 February 2017 - <http://www.the-star.co.ke/news/2017/02/17/betting-firms-oppose-midiwobill-claim-its-fundamentally-flawed_c1508208> on 14 June 2017.

28 Wanambisi L, 'No bet, gaming operators tell Midiwo on new law' Capital News, 17 February 2017 -<http://www.capitalfm.co.ke/news/2017/02/no-bet-gaming-operators-tell-midiwo-on-newlaw/> on 12 June 2017.

29 Wanambisi L,' KRA says Midiwo regulations 'bad bet' for economy' Capital Business, 21 February $2017 \quad-<$ http://www.capitalfm.co.ke/business/2017/02/kra-says-midiwo-regulations-bad-beteconomy/> on 14 June 2017.

30 Ngirachu J, 'Midiwo's Bill on betting appears headed for rejection’ The Daily Nation, 18 February 2017 -<http://www.nation.co.ke/news/midiwo-bill-on-betting-appears-headed-for-rejection/10563818738-bd5nrk/index.html> on 3 July 2017.

31 -<http://www.the-star.co.ke/news/2017/02/21/kot-attack-midiwo-over-betting-bill-say-hewants-money-from-companies_c1510728> on 12 June 2017.

32 Mbaka J, 'Midiwo stands his ground on betting bill' The Star Newspaper, 14 February 2017-<http:// www.the-star.co.ke/news/2017/02/14/midiwo-stands-his-ground-on-betting-bill_c1505917> on 10 July 2017. 
The Budget for the financial year of 2017/2018 was read much earlier than the ritualistic mid-June reading in anticipation of the August 2017 general elections. ${ }^{33}$ Cabinet Secretary for the National Treasury, Henry Rotich, hit gaming operators below the belt. He proposed a change in taxation for betting, lottery, gaming and competition to a uniform tax of 50 percent. He justified this by claiming that the industry was inadequately regulated and directed that proceeds be allocated to the National Sports, Culture and Arts Fund to support the development of sports, culture and art in the country. ${ }^{34}$

Following the reading of the Budget, the Finance, Trade and Planning Committee, with the backing of MPs argued successfully that the 50 percent uniform tax rate was too retributive and hostile for investors and would effectively cause them to pull out of the Kenyan markets..$^{35}$ After the initial rejection of the Finance Bill on account of the mirrored taxation rates present in the BLGA and giving recommendations aimed at raising the tax on betting, President Uhuru Kenyatta signed the 35 percent uniform tax rate threshold present in the Finance Bill which put an end to the push and pull of the tax to be levied. ${ }^{36}$

\section{Public Good versus Private Profit}

As regards sports betting, there are two conflicting sides of the argument: protecting the country against the potential repugnance of sports betting can be considered a public good. This is premised upon the fact that sports betting is considered a vice in society and should therefore be regulated. The second side is private profit which states that bookmaking and enforcing sports betting operations is a commercial venture and should therefore be allowed to thrive, like other businesses.

33 The National Treasury, Budget Statement for the Fiscal Year 2017/2018, 30 March 2017, para. 1 and para. 2.

34 The National Treasury, Budget Statement for the Fiscal Year 2017/2018, 30 March 2017, para. 156.

35 Mutai E, 'MPs to vote again on 50pc betting tax' The Business Daily, 28 May 2017 - < http://www. businessdailyafrica.com/economy/MPs-to-vote-again-on-50pc-betting-tax/3946234-3945744unuogg/index.html> on 10 July 2017.

36 Nsehe M, 'Kenyan sports betting firm SportPesa ends local sport sponsorship over gambling tax hike' Forbes Magazine, 24 June 2017 - <https:/ /www.forbes.com/sites/mfonobongnsehe/2017/06/24/ kenyan-sports-betting-firm-SportPesa-ends-local-sport-sponsorship-over-gambling-taxhike/\#58a4488f5674> on 20 June 2017. The uniform tax rate was meant to replace the earlier proposed rates in the Finance Bill as stipulated. See Section 80, Finance Bill (Act No. 38 of 2016). This is because the Bill mirrored the rates in the BLGA in order for the rate in the Budget not to take effect but President Uhuru Kenyatta recommended a uniform 35 percent rate of taxation. 


\section{i. Public good}

There are normative considerations affecting the public good that cannot be ignored by law and policy makers such as: regulatory lacunas and social factors like addiction to gambling, that are detrimental to the common good.

\section{a. Ambiguities in the law}

The high prevalence of Kenyans' participation in sports betting is a result of technological advancements. Ownership of a smart phone by the average Kenyan, the availability of mobile network and internet access to participate in such games, can explain this reality. ${ }^{37}$ Betting is widely advertised on television, colourful billboards and posters. Therefore, the law should regulate technology and its use by citizens, and in this case the advertisement of sports betting.

However, the material laws that regulate advertising of sports betting are vague. The advertisement of betting operators is prohibited if and when approval has not been granted by the BCLB. ${ }^{38}$ If the purpose was not the regulation of advertisement why would the section read: 'Prohibition against advertising of betting' instead of 'prohibition against unapproved advertising of betting'? Such an ambiguity must be addressed as it has rendered the industry devoid of regulation.

This is seen in $N W R$ \& another $v$ Green Sports Africa Ltd where the defendant, a sporting organisation, erected a billboard using the two Plaintiffs who were minors at the time, promoting sports betting on behalf of the Second Respondent, Acumen Communications Limited; a company affiliated to mCHEZA, a gaming operator. Upon confrontation, the First Respondent attempted to pay the parents off to avoid litigation. The court held that the use of the minors in the billboard was in contravention of the Constitution, ${ }^{39}$ the Children Act, ${ }^{40}$ and international conventions that guarantee the rights of the child, since it violated the privacy rights of a child granted by the Constitutionespecially because the guardians of the children did not consent to it. ${ }^{41}$

If the general industry practice of associating children with betting as outlined in the $\mathrm{BLGA}^{42}$ was not only clear but also adhered to strictly, such

7 Gemba A, 'Implications of sports betting in Kenya: Impact of robust growth of the betting industry', 12-13.

38 Section 25, Betting, Lotteries and Gaming Act (Act No.9 of 1966).

39 Article 53, Constitution of Kenya (2010).

40 Section 4(2), 13, 18, 19, 22 and 76, Children Act (Act No. 8 of 2001).

${ }^{41}$ NW R \& another v Green Sports Africa Ltd \& 4 others (2016) eKLR.

42 Section 28, Betting, Lotteries and Gaming Act (Act No. 9 of 1966). 
circumstances would be avoided. Despite not being invoked by the courts, the particular section states that a person is guilty of an offence and shall be held liable if they intentionally send a young person ${ }^{43}$ information relating to betting. Does it then not add up that the intentional use of a young person to advertise betting should be an offence too ${ }^{44}$ The premise upon which the judgement was made would have been more accurate if there was a law pertaining to the unquestionable illegality of advertising betting using a young person. ${ }^{45}$

\section{b. Addiction}

Sports betting has become addictive for many Kenyans. By 2016, three hundred thousand Kenyans were taking part in the weekly jackpot ${ }^{46}$ motivated by technological advancements such as the use of mobile money or, 'virtual wallets' ${ }^{47}$ This demonstrates that unlike before, one need not queue at bank halls, which has improved access to related facilities. The ease of access to these other similar facilities has incentivised sports betting and consequently perpetuated addiction. Indeed, Kenyans have been identified as one of the biggest gamblers in Africa with over 75 percent of the people aged between seventeen and thirtyfive years admitting to having taken part in it. ${ }^{48}$

A study conducted on students of Kisii University revealed that 50 percent of the students bet at least once a week, 28 percent at least once every fortnight, 12 percent every month and 2 percent at least once every three months. ${ }^{49}$ The dependency is so high that 50 percent of the students sampled often miss time at school while 40 percent stated that they often play truant as well. ${ }^{50}$ Some have become such compulsive gamblers that the activity has led them to insomnia, and

43 For purposes of the Act, a young person is a person who has not attained the age of 18. See the definition in Section 28(2), Betting, Lotteries and Gaming Act (Act No. 9 of 1966).

44 Section 48, Betting, Lotteries and Gaming Act (Act No. 9 of 1966).

45 Young person in the Act is the legal terminology used to refer to minors. See Section 28, Betting, Lotteries and Gaming Act (Act No.9 of 1966).

46 This is according to a study carried out by PwC in 2016 as cited by Gemba A, 'Implications of sports betting in Kenya: Impact of robust growth of the betting industry',3. This was described as a conservative figure.

47 Gemba A, 'Implications of sports betting in Kenya: Impact of robust growth of the betting industry', 4.

48 Nsehe M, 'Kenyan sports betting firm SportPesa ends local sport sponsorship over gambling tax hike' Forbes Magazine, 24 June 2017 - <https:/ /www.forbes.com/sites/mfonobongnsehe/2017/06/24/ kenyan-sports-betting-firm-SportPesa-ends-local-sport-sponsorship-over-gambling-taxhike/\#58a4488f5674> on 20 June 2017.

49 Koross R, 'University students gambling', 62.

${ }^{50}$ Koross R, 'University students gambling', 63. 
the use of sleeping pills. ${ }^{51}$ The vice has also been linked to vicarious trauma. ${ }^{52}$ To accommodate losses, some sell their belongings to finance their addiction and even use their HELB loans to support their vice. ${ }^{53}$ Students have defaulted on their school fees, failed to sit for their examinations, and eventually drop out. Some, such as one Kabianga University student, commit suicide after losing a bet. $^{54}$

Perhaps the deficient regulatory framework implicitly grants industry operators the permission to operate at the expense of the fabric of society. It would be irresponsible for policy makers and other interested parties to further allow the laissez faire operation of sports betting in the nation as it runs the risk of jeopardising the public good of the Kenyan people. Often, gambling attracts the vulnerable groups of the society. ${ }^{55}$ It is towards this end that the state has the obligation to exercise its fiduciary duty and guard its citizens, jealously.

\section{ii. Private benefit}

\section{a. Sport sponsorships}

Sports betting has granted football teams considerable sponsorships on the international football scene, improving their football careers. ${ }^{56}$ In Kenya, the same has been replicated. SportPesa, the pioneer betting operator in Kenya, currently sponsors top teams in the Kenya and English Premier Leagues. ${ }^{57}$ These sponsorships can place local teams on the international sporting map. Gor Mahia, for instance, played a friendly match against Everton in Tanzania; ${ }^{58}$ giving the Kenyan team more confidence and exposure than they had before. A couple of years ago, this would probably be unheard of; not because Kenyan football

K1 Koross R, 'University students gambling', 63.

52 Kariuki M, Kathuku D, Owiti F, Auka J and Kariri J, 'Evaluation of the severity of vicarious trauma among students at the Kenya Medical Training College, Nairobi Campus, Kenya' 5(10) International Journal of Innovative Research and Development, 2016, 137.

53 See Koross R, 'University students gambling', 64. HELB loans are government funded student loans for tertiary education, usually lent to students who may not be able to afford their tertiary education.

54 Koross R, 'University students gambling', 59 and 64.

55 Gemba A, 'Implications of sports betting in Kenya', 16.

56 Anderson $\mathrm{M}$ et al, Sports betting, vii.

57 Nsehe M, 'Kenyan sports betting firm SportPesa ends local sport sponsorship over gambling tax hike' Forbes Magazine, 24 June 2017 - <https:/ /www.forbes.com/sites/mfonobongnsehe/2017/06/24/ kenyan-sports-betting-firm-SportPesa-ends-local-sport-sponsorship-over-gambling-taxhike/\#58a4488f5674> on 20 June 2017.

58 Farrell D, 'Gor Mahia 1 Everton 2: Rooney marks return with long-range strike', Goal News, 13 July 2017 -<http://www.goal.com/en-ke/match/gor-mahia-v-everton/8512c6woupzxvyxyq7swx jeqy $>$ on 27 July 2017. 
players lack talent, but because Kenyan football and sports in general have been riddled with challenges which have rendered the industry dormant. ${ }^{59}$

Private corporate sponsorships have helped to lift this burden, as a way of practising Corporate Social Responsibility. ${ }^{60}$ Betting operators are not the only companies that have presented this opportunity; however, their contribution to Kenyan football has been unequalled. This therefore signals that sports betting has brought along gains for bookmakers and the football sector in Kenya and deserves a seat at the commercial table on this account; a matter which has not seemed to elicit the best responses.

Following the presidential assent of the Finance Bill which affirmed that betting, gaming and lotteries would all be taxed at a uniform rate of 35 percent, SportPesa sent notice to withdraw its sponsorships of Kenyan teams in January 2018, asserting that the rate would be too high for the venture to be a worthwhile investment for the company. ${ }^{61}$

Perhaps this note should paint a clear picture of the sports sector in Kenya to justify the attitude of entitlement that has been demonstrated by the actions and apparent attitude of the betting operator SportPesa. Mismanagement of funds, inadequate funding, a few but hardly enough corporate sponsorships in some instances, insufficient relevance of arts and talent-based careers in the economy and negligence by the sports ministry are not the only challenges the sports industry faces. In 2016, the National Olympic Committee of Kenya demonstrated great disorganisation and disregard for the Kenyan tax-payer in the 2016 Olympic games where the Kenyan team lacked sufficient transport, was almost excluded from participation due to non-compliance and lacked gear for the opening ceremony despite sponsorship by Nike; ${ }^{62}$ which led to a formal complaint being lodged in the Office of the Deputy President. ${ }^{63}$

\footnotetext{
Nyingi P, Kenya wins a gold medal for corruption, March 2017, 1.

6 'The importance of good sponsorship in football' The Daily Nation, 1 March $2017-<$ http:// nairobinews.nation.co.ke/sports/importance-good-sponsorship-football/> on 12 June 2017.

${ }_{61}$ 'SportPesa to end Kenya football league sponsorship over tax' BBC News, 23 June $2017-<$ http:// www.bbc.com/news/world-africa-40385653> on 30 June 2017.

62 Nyingi P, Kenya wins a gold medal for corruption, 1.

63 Nyingi P, Kenya wins a gold medal for corruption, 2.
} 


\section{Other Factors to Consider}

Taxation is a measure that is imposed on the workforce. This includes corporate persons operating in Kenya's economic atmosphere, evident in the Income Tax Act. The corporate tax rate is to be levied on corporations at 30 percent. $^{64}$ According to the aforesaid sentiments of the AGOK, betting operators pay corporate tax as they demanded that their field of betting is just like any other economic activity and deserves to be taxed as such. ${ }^{65}$ This does not concur with the fact that owing to the additional 35 percent uniform tax, betting operators are paying nearly 65 percent $^{66}$ of their gaming revenue as tax when both taxes are combined. This seems rather punitive as the government seems to have neglected their plight in not allowing them to make profit like any other commercially viable activity.

Indeed, the sports betting industry deserves regulation and qualifies for sin tax, ${ }^{67}$ but a total tax rate of 65 percent, ${ }^{68}$ is too disproportionate to be deemed as profitable. Furthermore, taxation is not the only regulatory method ${ }^{69}$ but this proves that the sports betting law in Kenya needs to be enriched. For the same reason, it should be practised and given scholarly attention.

Thirdly, it is fundamental that the government focuses on protecting the interests of its people rather than gamble their fate and socio-economic structures. If not for the sake of goodwill, at least in fulfilment of the social contract theor $\mathrm{y}^{70}$ whose seal is the preamble of the Constitution and general elections carried out every half-decade to choose the government of the day.

When carrying out the reforms, the government should institute policies that prioritise the outcome for the people. ${ }^{71}$ This is not to say that mercantilism is the way to go or that we should reject the inclusion of some people in our economic policy; but given the high growth rate of the industry, it is necessary to

64 PwC, Kenya Corporate taxes on corporate income, 1 June $2017-<$ http://taxsummaries.pwc.com/ID/ Kenya-Corporate-Taxes-on-corporate-income> on 23 June 2017.

65 Section 2, Income Tax Act (Act No. 19 of 1972).

66 Sixty-five percent has been arrived at by summing up the thirty percent corporate tax and thirty-five percent uniform tax.

67 Sin tax, also known as excise tax, is a tax levied on goods and services that may be considered as repugnant to public morality and hence require regulation.

68 This figure has been arrived at after adding the 35 percent tax rate present in the Finance Act and the 30 percent tax rate to be paid as corporate tax.

69 Other regulatory methods include the restriction of gambling activities to certain geographical locations, as is the case in the United States of America as aforementioned by the author.

70 See generally Rousseau J, Social contract \& discourses, EP Dutton and co, New York, 1913.

71 Article 1, Constitution of Kenya (2010). 
protect the interests of the people. We should particularly take heed of the fact that some investors are of foreign descent and may not necessarily feel obliged to do right by Kenya. This is not to deny that Kenyans have free agency to participate in sports betting. ${ }^{72}$ It is therefore necessary to be forearmed.

In addition to placing paramount the interests of the Kenyans as a people, the government is beyond question obliged to pay heed to the reason(s) why gambling was legalised in Kenya back in 1966. Taxation was sought in order to regulate the activity rather than ignore it, as it had taken root in society. That which was sufficient then does not suffice now. Contextually speaking, the BLGA fit the bill at the time of its inception as it effectively controlled the small industry, but this does not hold water anymore since what was once taboo is now an economically viable activity and should be regarded as such. Regulatory measures should not be used to kill the market. On the other hand, gambling is a vice, and despite its economic strength and contribution in Kenyan sports it should not be exempted from sin tax or from regulatory measures that would somewhat discourage the public from taking part in it. The measures must not be too few to be insignificant nor too many to be castigatory.

\section{Conclusion and Recommendations}

The lack of concordance between interested parties in the gambling industry and the government authorities has resulted in the locking of horns. Sports betting in Kenya has caused a social, political, and cultural dilemma. The solution can be made tactfully to accommodate the economic interests of AGOK and other interested parties. The stance taken by this note is that the gambling industry in Kenya should be regulated but need not be made redundant as it is an economically beneficial sector and has contributed to the increase in revenue for the nation, and the employment of people especially in the sports industry, football in particular. It should therefore be given a conducive economic environment to grow even further. In the same vein, it should not be left to its own devices to be its own monopoly as this would mean social and economic decline to some extent.

\footnotetext{
'Echoes of past as Midiwo betting Bill goes after foreign investors' The Standard, 7 February 2017 - $<$ https://www.standardmedia.co.ke/business/article/2001228505/mp-midiwo-s-betting-billgoes-after-foreign-investors> on 12 June 2017.
} 
A deliberate and transparent dialogue led by a neutral party should be carried out between the government through the Ministry of Finance, KRA and the Ministry of Sports, Culture and Arts as well as betting operators through AGOK, BCLB and other interested parties. Public participation ${ }^{73}$ should be regarded highly in this particular dialogue and all parties involved should take part in making an agreeable compromise on the way forward. The resolutions of the dialogue should inform reforms in law and policy making. A discussion on alternative regulatory measures of sports betting would be important. South Africa displays a counter-intuitive reality that its sports betting operations generate the highest turnover in Africa because it is highly regulated; which gives more comfort to willing investors. This means that not only should the law provide safeguards to protect the bettors but also incentivise investment to strike the balance between the two. Following the dialogue, the ambiguities that are present in the law must be addressed by legislators and if this necessitates that a Bill be proposed, a member of the National Assembly should be approached for its sponsorship.

The government should educate the public on sports betting and its effects so as to equip people against its dangers. This may be done in conjunction with the Ministry of Sports, Arts and Culture through advertisements, pamphlets and flyers, and holding talks and symposia in institutions. In addition, such an initiative may be an appropriate form of Corporate Social Responsibility for betting firms; for instance, through the sponsorship of gambling addiction therapy. ${ }^{74}$ The use of warnings of the addictive effects of sports betting on billboards and other advertising media may help in keeping consumers aware of the potential dangers. This could protect the most vulnerable who are easily swayed by the hope of 'winning big'. Mass education would not only be a deterrent but would also urge bettors to bet with caution and reason. This would discourage instances where people bet away all their wealth.

One integral step towards the development of the law is the scholarly contributions of people within the legal fraternity. Legal writers, as well as writers in the field of economics, social and political science should study the issues concerning sports betting in the nation and help seal the gaps that the law has not yet taken into consideration, by undertaking diligent research.

\footnotetext{
Public participation is part of the national values and principles of governance as seen in the Constitution. It is a process of stakeholder engagement where the people of the nation are involved in making decisions that will affect them. See here Article 10, Constitution of Kenya (2010).

74 Notes with author.
} 